\title{
The interactive museum and its non-human actants
}

JONATHAN WESTIN*

\begin{abstract}
This explorative study highlights the different strands of interactive learning technologies available to museums and educational institutions, and analyzes their function as non-human actants from a perspective of power and discipline. Through a generalized symmetry I describe a specific technology - the interactive display - as an actant exercising the same autonomy as the other actants. This raises the non-human actant to the same level as the human actants and emphasizes how it controls an equal part of the communication. In this way I try to map out how an exchange is manifested through a network of actants where the technologies conserve the inquiring actant's knowledge space rather than broaden it. Despite being offered as a technology to make the visitor heard, the result is as curated as the classic exhibition. I conclude that by themselves, interactive displays do not challenge authority at museums but instead reinforce it.
\end{abstract} Key words: Interactivity, non-human actant, technology, communikation.

Scene 1: The visitor contemplates the reconstruction in front of her. It is a digital rendition of the Sanctuary of Hercules Victor. At first glance it looks static, but then she notices that it is slowly changing into an alternative interpretation of the same space. And then another one! This catches her eye. The visualization is open; she can interchange various elements or completely remove them. She can cycle between different versions of the same scene and choose from a library of available media presenting different aspects of the sanctuary; sound clips, animations and text. As she cycles between the different elements of the visualization - removing a wooden structure here and changing the colours of a wall there - she notices that with every variation comes a bibliography of publications that support or discuss that very interpretation. She scribbles down the name of an article that seems interesting (Sanctuary of Hercules Victor).

Scene 2: A coloured trail winds through the landscape. It pulsates and beckons. She starts running, following it over rocks, crossing a brook and in through the trees. Suddenly she sees her goal; a stag! Motionless they stand observing each other, looking for signs of imminent action. How can she notify her pack about her prey? She pushes the H-key and howls. Seconds later the land is alive with responses. It was very effective. Exiting the simulation she seeks more information about this behaviour online (WolfQuest). 
46 Interactivity, learn-through-play, participatory elements, community building and augmented reality; technologies all at the heart of the future of exhibitions. Not to be perceived as stale, many museums are slowly embracing the post-modern notion that history - and society - is a multitude of conflicting and unique voices and that the museum should be a meeting place where these can be made heard (Westin 2009). In this tradition they nurture a positive wish to position the exhibition as a heterogeneous dialogue instead of a homogeneous monologue - a communication where the visitor's voice is an important aspect of the exhibition and should therefore be engaged. Technology in the shape of the interactive digital display is often seen as the most fitting instrument to establish this dialogue (Witcomb 2007; Santillo Frizell and Westin 2009). In this new milieu, the visitor is free to choose her own path, sort through conflicting reasonings and shape her own experience. Where a museum visit was once a collective experience where a common objective message, pace and order were set, the interactive display allows for alternative subjective narrations.

Susan Hazan argues that media applications serve to "enhance and extend the museum mandate in novel ways, and even open up new possibilities for those who may have conceptualized themselves outside of the museum, to be able to find a way in" (Hazan 2007: 134),. This article shares this sentiment, but my view differs when it comes to the media applications' function as interpreters of information. Far from being neutral forces, I argue that although these participatory technologies are aimed at improving communication and education, they are above all else a disciplinary force - an impoverished realization of a two-way communication brought on by an unchecked technologydeterministic way of thinking. The technology in these 'spaces of interaction' - described as two distinct scenes above-constitutes a nonhuman actant that forces certain questions and subdues others, turning an infinite number of possibilities into a pre-programmed few. The focus this creates is an effective tool in education since it establishes a controlled milieu which allows for exploration within set limitations leading to the exact series of conclusions that are being taught. Without question, technology allows for new ways of reaching and teaching an audience (as exemplified in Kahr-Højland 2007; Hazan 2007; Kenderdine 2007; Awouters et al 2009; Anzai 2009; Cooper et al 2009), but it prevents new solutions from being expressed.

The aim of this exploratory study is to highlight two different strands of interactive teaching/learning technologies and analyze their function as non-human actant from a perspective of power and discipline, as described by Michael Foucault (Foucault 1978. Discussed in Westin 2009). By putting focus on power exercised by both sentient and nonsentient actants, I try to map out how an idea is manifested through a network where the technologies - to the same extent as the humans - uphold a knowledge space and enforce it (see Latour 1992; Ivarsson 2010). Furthermore, this study attempts to explain the practical ramifications of moving the communication to an interactive milieu where action has to be represented. While the technology in the network seemingly allows action, it is its capacity to forbid action - to limit - that makes it an interesting actant we can follow. These limitations shape our interaction with what is presented through the 
representation in the virtual space of the display, and decide what can and what cannot be expressed. A representation is a rethought substitution for an event - not the event itself - where a layer of interpretation and focus has been added. Hence, the complexity of an event is displaced by a manageable representation that can be communicated, but is in this act translated to something new.

I argue that you can never directly act in the interactive space, only choose between a series of predefined re-actions, which translates that the interactivity subject to this study is not about releasing power, but about forcing certain answers. This is a problem when an exhibition wishes to use interactivity as a technology to entice an audience to enter a dialogue, since - as this paper proposes - digital interactivity does not in its current form support that kind of communication. As a growing number of museums and educational institutions move their communicative ambitions into a digital space, a lack of understanding about the non-human actants that reside in most communicative technology could result in a dialogue that is conservative rather than progressive. It is therefore important when designing interactive displays that the limitations of interactivity are recognized, since they constitute a disciplining of the subject not always intended. To discipline the communication between two subjects is in itself not wrong, and it can be argued that it is often the preferred model, but digital interactivity should be revised or combined with other venues of communication in situations where it is important that the opinion - or knowledge - of a visitor can be expressed.

In terms of structure, I approach this issue by dividing the article into two main parts. In the first I try to define what technology is in a museum context, while I in the second describe and analyze two empirical studies of interactive communication in an attempt to argue my thesis. The interactive spaces studied have been chosen for their diversity as well as the amount of material they have afforded. Though they are not presently deployed at any museum, they represent two typical examples of interactivity aimed at communicating research to an informed third party. They have their technical counterparts in numerous museums around the world and will be a common sight in future exhibitions. The first of the two spaces, the Sanctuary of Hercules Victor, has been codeveloped by the author as part of an interdisciplinary research project on heritage management and communication - giving access to both the reasoning behind it and its technical specifications - while the second interactive space, WolfQuest, has been thoroughly studied from its inception to its present state. The interactive display of the Sanctuary of Hercules Victor was presented at a press event in Rome 2009 at the Swedish Institute of Classical Studies on the occasion of a state visit by the King and Queen of Sweden. Present were the Swedish Minister of Education, the Soprintendenza Archeologica di Roma e del Lazio and representatives from several of the foreign scientific institutes in Rome. Since then, the display has been presented at various institutes internationally as an example of the possibilities of interactive displays and how they could be used in a museum setting. It demonstrated how a representation shapes our perception of an occurrence, and how the visual language could be used to encourage the audience to understand that there exist many possible interpretations. WolfQuest is a freely available 
48 precursor to the immersive digital representations of historic settings thought to become a common sight at many museums in the future as collections give way for context. By visualizing this context through displays and virtual reality settings, it becomes "mobile, immutable, and reproducible" (Hermon 2008: 37; Latour 1986). WolfQuest has been awarded prizes by several institutions, including a 2009 MUSE award from the American Association of Museums and an official selection by the National Science Foundation in the US to make a presentation at the 2009 Senate Education Technology Showcase in Washington D.C. (www.wolfquest.org/about_overview.php).

\section{Methodology}

As a method, I lean heavily on Actor-Network Theory (ANT) and the work of Michel Callon and Bruno Latour (see Callon 1986; Latour 1992; Latour 1993; Latour 2005). I describe the exchange between the two communicating parties and the technology through which they communicate as they were all actants capable of action. Through this generalized symmetry a structure consisting of three subjects becomes apparent, a structure which is then analyzed in its capacity of allowing or limiting action. ANT is a sociology of associations which map out how material and semiotics are combined into a whole that is constantly challenged and confirmed through negotiations. Just as in the power theories of Foucault, where power is not something you can own, only exercise, the actor-networks need to be active not to fall apart. A network is therefore not a constant but always new and dependent on all actants' collaboration. An actant is a neutral term that includes both actors capable of action and systems that simply behave. An actant, like a machine or technology, could consist of several micro-actants important to the macro-actant but possible to ignore until the macro-actant fails in some way. Consider a computer. Until it starts behaving erratically, flickering and turning itself off, it is to the end user a single actant akin to a black box (Latour and Callon 1981). However, if the user opens it up, trying to fix it, it stops being a single actant and becomes a network of actants - circuit boards, power inverters and CPU fans - all vital to the computer but until recently something that the end user could ignore. Apart from the actants that make up the technology of an interactive display, I will for this article not dwell on all the actants that make up a museum or visitor.

In the communication network between two actants, A and C, through a third actant, B, they all need to perform their duties in the network for communication to work. If the third actant - the technology through which A and $C$ interact - stopped functioning or if actant $\mathrm{C}$ refused to acknowledge actant $\mathrm{B}$, the network would dissolve and communication would be interrupted. For a new network to establish itself and for the communication to continue, all actants must re-negotiate their positions in a way that makes them accept and perform their duties. How can actant $\mathrm{A}$ and $\mathrm{C}$ formulate themselves in a way that is both true to the message and allowed by actant $\mathrm{B}$ to be expressed? How can actant B mediate this communication in a way that allows actant $\mathrm{A}$ and $\mathrm{B}$ to understand each other?

Actant B, the technology, emerges here as a mediating actant - an actant that transforms the communication to make it mobile - and not a neutral intermediary, since both actant $\mathrm{A}$ and actant $\mathrm{C}$ need to adapt their message to a form that actant B allows. This adaptation is in ANT 
terminology referred to as a translation where the offspring is a hybrid, the result of a negotiation between several actants. To make this process visible, and to show how an open communication is translated into an enforced structure through supposedly neutral technologies, I intend to map out the negotiation process in the initially described interactive spaces. This to problematize interactive media as a mediating actant that plays an increasingly larger role in museums' communication with their visitors. Before that, however, I wish to flesh out a definition of technology in a museum context where previous technologies have shaped the institution and future technologies help conserve or develop it.

\section{Museum technology / CREATING THE ARTEFACT}

The museum - though often perceived as a conservative space - has always relied on technology all through the process of preservation and exhibition, and as a consequence it has been shaped as an institution by that very technology. Likewise, the object, and how we perceive it, has forever been changed. It is turned into a museum artefact disconnected from its original context - as a result of how it has been processed through all the transformations that the technologies of a museum make up. The technological process that transforms an object into a museum artefact - or museal fact, as Grahn puts it (Grahn 2005) - includes a written description that decides what aspects are important; photography that decides how it should be remembered; conservation efforts that decide how it should be perceived; exhibition design that decides how important it is; spotlights that render it neutrality and displays that decide how it should be understood (see Goodwin 1994 for an analysis of how an archaeological site is organized through the use of technology). This process does not end with the physical artefact but extends into its digital representation where visual, dimensional, locational and environmental aspects are translated into images and numbers (for an account of this process see Arnold 2008).

Just as past technologies have shaped our perception of the museum object, new technologies often help conserve this perception instead of bridging the gap between object and visitor. So why talk about these latest technologies in museums and education as something different? Because they are communicative technologies that encourage action on behalf of the visitor. As an increasing number of questions are raised concerning the shaping of knowledge and what ideologies govern an exhibition, an outspoken objectivity is not enough (Stead 2004: 6). Technology - in the shape of inclusive displays that encourage the visitor to contribute - is thought to remedy this by exposing the subjectivity of history. However, an ever-present risk with interactivity is that it disciplines the actant into a structure of finite choices rather than creating a milieu which allows alternative interpretations to be expressed. Instead of communicating that there are several different ways of interpreting an occurrence, it can be understood as if the presented choices are the only choices, effectively solidifying their status. This is a byproduct of how interactivity imperfectly caters to the body's function as both receptor and transmitter - while it stimulates reception, it allows only reactions to transmit and not actions (Westin 2009). In that perspective, that which the museum believes to be a relaxing of 
the old subject-object power relations is really just a repackaging which enforces the structure.

\section{The non-human actant}

By letting the visitor's body become a part of the exhibition, you engage her analogue senses and create a connection. In the physical interactivity of the classical science museum, the body fills the function of powers - it creates movements and connects elements. This differs from the digital interactivity present in humanistic arts where interactivity does not always trace back to the activity, or reactivity, of the visitor's body in other ways than through choices. However, the goal is the same; activate the visitor in a way that makes her involved in the exhibition and makes her feel more like a contributor than a visitor and more like a creator than a user, thus promoting a creative reasoning that trains her inductive problem solving skills (for a discussion of the positive effects, see Greenfield 2009; Lee 2009). Neither a user nor a visitor can be a target group since these are descriptions of occurrences tied to a body for a finite period of time. It is therefore not practical to address them as a social/psychological group or demographic (Barry 2001: 135). Of course, a body can be compelled to use, or visit, something on a regular basis creating a user situation or an active visitor.

An active visitor is created by presenting a for the recipient - attractive end result as highly accessible, which makes the actions to reach a certain goal tractable. In user interface design this is traditionally measured in steps or choices, where the optimal solution is the one that requires the lowest amount of conscious reactions to reach a certain goal. It should be noted that the above sentence reveals the complexity of the problem; the digital interface can't allow access to every part of an intricate system from one point in an effort to reduce steps since that would expose the user to too many conscious choices to be meaningful. Likewise, the interface cannot compartmentalize every choice since it would introduce too many reactions in reaching the required goal and therefore be perceived as less tractable. To manage this conflict, the interface anticipates what the user wishes to do and guides her. Herein dwells the "Non-Human Actant"; digital interactivity must by design be a series of possibilities presented as choices in a hierarchical structure and those choices are non-negotiable (Westin 2009). By introducing limitations in the form of choices, the user is guided by the non-human actant residing in the structure of interactivity, not by a person she can communicate freely with.

In a simple interactive space, two alternatives are being presented by the interface. Thus, the visitor has three choices; Pick 1, pick 2 or leave it as it was. However, she may choose, she has defined herself as a re-active object in this structure - she has relented to the will of the interface, since those choices have been prepared and therefore only reflect the knowledge put into the interface by the programmer, and not the knowledge of the visitor. When you accept an option, you always re-act, never act. Hence, the dialogue between two subjects has been displaced by a formula where the responding subject is limited to expressing what the inquiring subject allows. The technology in this network of actants consists of a Non-Human Actant that promotes and solidifies a reasoning; Communicating Actant A (the Museum) that communicates with Communicating Actant C (the Visitor) through Mediating Actant B (the Technology) that disciplines Actant $\mathrm{A}$ into certain questions 
and Actant $\mathrm{C}$ into certain responses. Actant $\mathrm{A}$ can then remove itself from the conversation and does so quite often - and let Actant B handle Actant $\mathrm{C}$ all by itself, creating a milieu in which no new opinions can be voiced.

\section{STRANDS OF INTERACTIVITY: LABYRINTH AND SIMULACRA}

Power relations expressed through communication - both inside and outside the museum - take many forms and may not always be apparent. By identifying action and reaction - along with consumption - as a distillation of the processes that make up interactivity in the digital space, we can analyze different forms of communication to see how they are disciplined. Below I give a short description of two interactive models which I argue represent two distinct types of teaching/ learning situations, where communication is established through a digital interface set to engage an audience in exploring layers of information in a way that aids a deeper understanding. The aim is not to give a comprehensive account of all elements of these interactive spaces but to identify and communicate the role of the "Non-Human Actant". These descriptions will constitute the empirical material of my analysis.

The main focus of this paper is the digital form of interactivity, and I only briefly mention the physical form of interactive displays. Additionally, I am mostly concerned with the communicative aspects of interactivity where the technology is used to create a connection, and I will therefore primarily address the strands of interactivity aimed at communicating research. Through this narrowing- down process, I have identified two types of interactivity. I will refer to the design of a digital space the visitor is expected to navigate at his or her own leisure as labyrinth interactivity. This interactivity is not limited to the navigation of digital representations of physical rooms - the space that labyrinth interactivity concerns itself with is a space of stories, movies, interviews, texts and images that can be consumed and presented in any variation and constellation. Labyrinth interactivity, as a pedagogical tool, is prevalent in the humanistic arts. Museums are frequently using labyrinth interactivity in their exhibitions when they offer up a selection of information in the form of text or audio clips, images and movies. In historical museums, interactivity is often presented as a freedom of paths or a shuffling of cards. Information can here be digested at the visitor's own pace through different media and augmented reality. Through the interactive display, the visitor can pick what she is interested in, go back and forth in the hierarchy of options, or simply choose to follow the default pre-programmed path. Interactivity has a wider meaning than being a simple narration device; in a museum context it "promises to turn the unfocused visitorconsumer into the interested engaged and informed technological citizen" (Barry 2001: 129). This description is applicable to labyrinth interactivity since it can be used to foster an understanding for alternative branches within a given field.

The interactivity where the actant is shouldering a role - with its own specific rules - I call simulacra interactivity. This interactivity differs from labyrinth interactivity by including artificial restrictions based on the analogue conditions and relations it sets out to mimic. Simulacra interactivity differs from the labyrinth interactivity by introducing the simulation of a body. The reactions are filtered 


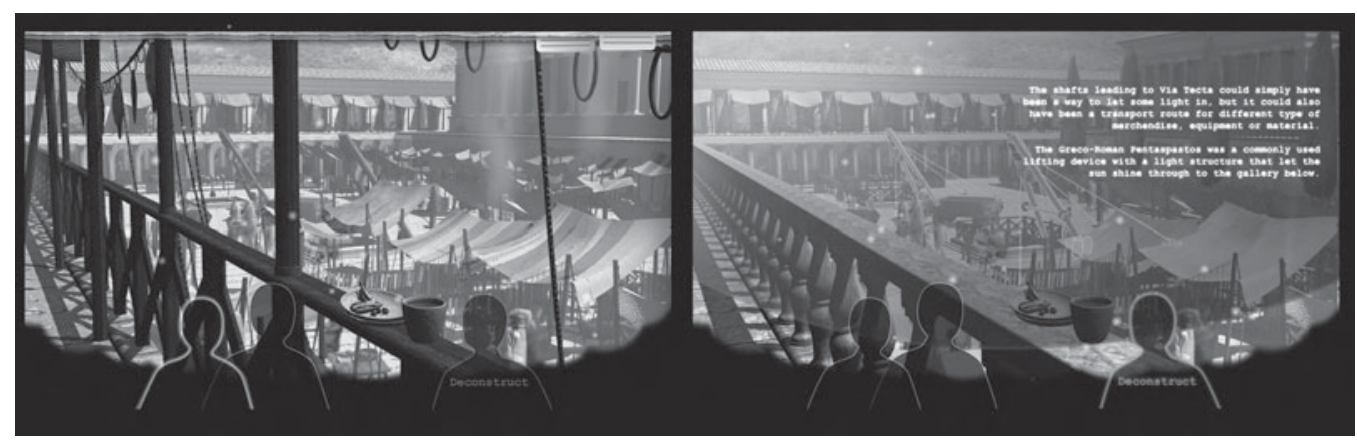

Fig: 1: The interactive visualization of the Sanctuary of Hercules Victor. (C) $2010 \mathrm{~J}$. Westin.

through this body. The body does not have to be a digital representation of an analogue body, but does consist of a series of restrictions that discipline the user into a modus operandi. These restrictions constitute an imperfect mimesis since they imitate the knowledge of the body not the body itself - and are changed through their translation into figures in the digital sphere. The actant entering the simulacra interactivity accepts the restrictions as tropic and works within them. The simulacra convey the idea that the figure is seen, and treated, as a perfect representation of reality. It is an aspiration of simulating reality with something that is perceived as a possible substitution for reality. NASA, developing a massive multiplayer game, sees the educational gaming platform as a persistent, synthetic environment supporting education as a laboratory (BBC 18.01.2008, Wired 21.01.2008, Wired 22.01.2008). "Virtual worlds with scientifically accurate simulations could permit learners to tinker with chemical reactions in living cells, practice operating and repairing expensive equipment, and experience microgravity[...] [It] will foster career exploration opportunities in a much deeper way than reading alone would permit and at a fraction of the time and cost of an internship program" (Laughlin 2007). The simulacra interactivity, like the simulacra of Baudrillard, produces an inter-link with the real that is tropic, but cannot be treated objectively as true or false (Baudrillard 1988: 166-170. See also Doel and Clarke 1999: 266).

\section{Labyrinth interactivity and the Sanctuary of} Hercules Victor

The interactive visualization of the Sanctuary of Hercules Victor consisted of a reconstruction - a scene depicting the templum of the sanctuary in Tivoli, Italy - that was mercurial in its constellation; the image shifted between two distinct versions of the same scene - one as a serene garden area and the other as a lively market. Most objects were removable, or could be changed into alternative interpretations which were supported by text that explained the reasoning behind them (fig. 1). The goal was to communicate an uncertainty rather than trying to convince the user of a truth, and give her the freedom to express her own interpretation of the space (see Santillo Frizell and Westin 2009 and Westin and Eriksson 
2010 for a comprehensive description of the project).

To reach this goal there had to be negotiations between a series of actants; the instigator, the media and the recipient. In the negotiations between the museum (Communicating Actant $\mathrm{A}$ ) and the interactive display (Mediating Actant B), the initial ideas of the museum had to be translated into a structure that was supported by the tools at hand. Technological possibilities, skill and time affected this translation and shaped how the interactive display mediated the idea to the visitor (Communicating Actant $\mathrm{C}$ ). Further, not to break the communication, the visitor demanded that the idea followed a certain structure for it to be understood - as a recipient she had to be familiar with the meaning of the components of the interface to be able to navigate the idea successfully - which further translated the idea into a collaboration between all three actants. Through this negotiation process the project took a detour from the initial plan - a plan which was interrupted by the visitor's perceived lack of interest - to a less complicated one that was considered better suited to the task of engaging the visitor. Only symbols and modality markers that the visitor would instinctively recognize were used. Options were reduced and simplified so that the visitor wouldn't feel overwhelmed, and the language was adapted to be comprehensible by non-scholars. The interactive display was made possible through a number of software applications, which all shaped the product: Strata 3D Studio CX 5, Adobe Photoshop CS3 and Adobe Flash CS3. A series of 3D models were first created in Strata 3D Studio CX 5, each reconstructing the scene differently. Key components were selected from each scene, rendered as high-resolution Photoshop documents with alpha channels, and then imported into Adobe Photoshop CS3, where they were assembled as a multilayer document. This allowed them to be combined in a variety of ways. Each component of the assembled Photoshop document was then exported as a PNG image with the alpha channel intact and imported into Adobe Flash CS3 as unique movie clips that could be interchanged using the ActionScript 3 language. The initial idea of the museum has now - by being codified in graphics, symbols, text and clear choices - been translated into a hybrid that both the interactive display and the visitor accepts. The interactive display acknowledges this by working and the visitor acknowledges this by partaking in the communication.

In making the components of the visualization interchangeable, the interactive display allows the visitor to express her ideas about the space by controlling the combination of components. A wooden rail or a stone balustrade? A coloured tent or a white canopy? Red or white columns? Hence, a finite space was created and offered up for exploration.

\section{Simulacra interactivity and WolfQuest}

WolfQuest, developed by Minnesota Zoo in conjunction with EduWeb (www.eduweb.com), is described in the press release as a wolf simulator aimed at educating the player about the wolf. Through the simulation of being inside a wolf body and being confined to those motions allowed by that body - lack of speech and hands, but with great speed, hearing and sense of smell - the visitor is expected to learn about the ecology of the wolf. In the character of a wolf, the visitor can freely move about a vast digital landscape populated by prey and other wolves with which she interacts (fig. 2). Furthermore, she is encouraged to seek 


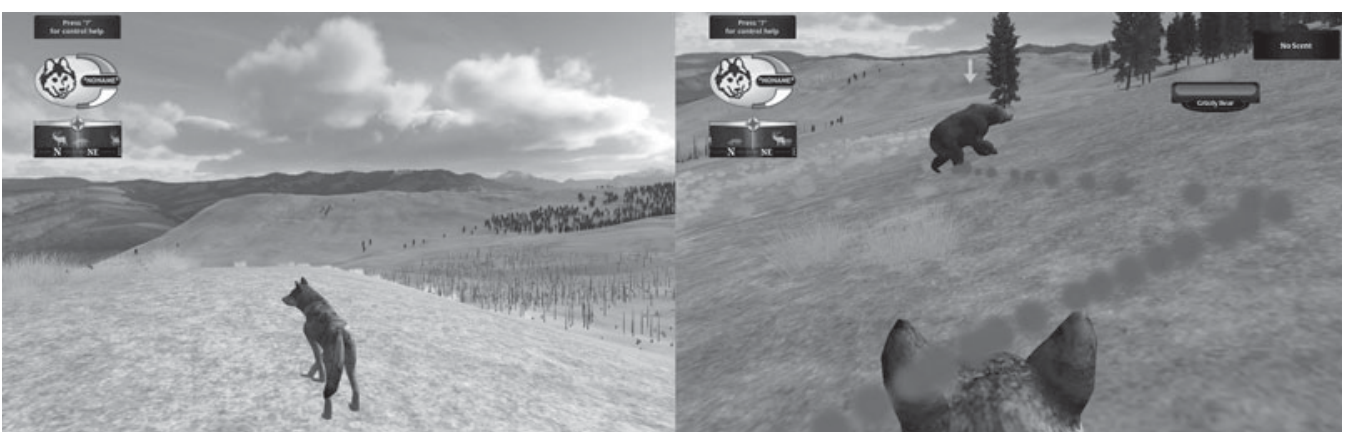

Fig 2: WolfQuest (C) 2010 Minnesota Zoo and Eduweb.

alternative sources - one such source being the wolf biologists available through the game's online presence - and contribute to the community through art and stories. So how do you create a digital wolf simulacra?

EduWeb (Communicating Actant A) had an assignment from Minnesota Zoo to create an interest in the ecology of the wolf through interactive media. The aim of this interactive media (Mediating Actant B) was to give the visitor (Communicating Actant C) a deeper understanding of the various aspects of a wolf's life. For there to be uninterrupted communication between EduWeb and the visitor, WolfQuest had to attract the attention of the visitor. This was achieved through presenting WolfQuest as a fun experience that let the visitor quickly learn through play. A translation on a grand scale was necessary; information was adapted and codified so the visitor could navigate it from a wolf's point of view. By putting her in the simulated body of a wolf and then let her experience and react to different situations that highlighted the ecology of a real wolf, she was both enticed to stay in or keep returning to - the interactive teaching/ learning space and gain an understanding for aspects of the wolf that are hard to obtain solely through literature. The developers choose Unity as a 3D game engine and brought in external expertise on both 3D modelling and game engine optimization to adapt their vision for the integrated authoring tool. Furthermore, they established an advisory committee to provide the project with additional expertise to inform both the design and dissemination of the project.

WolfQuest, as a teaching/learning space, had to be a product of EduWeb's collected knowledge about wolf ecology - obtained from Minnesota Zoo and a group of consultants where certain key characteristics were identified that could easily be communicated and learnt through experiences, or translated into stylized, turn-based social interactions. These characteristics were then turned into figures and, as a method to even out the learning curve, translated into a language of symbols that could both be processed and visualized by WolfQuest and which the visitor could relate to. A coloured trail represented lingering scent and a compass communicated the wolf's ability to "read" the land. The complex emotions involved in a howl were mapped to a single key stroke. EduWeb's and Minnesota Zoo's knowledge of the wolf has successfully, just as 
in the case of the Sanctuary of Hercules Victor, been translated into a hybrid that is both allowed by the interactive space and accepted by the visitor. Once again the interactive display acknowledges this by working and the visitor acknowledges this by partaking in the communication, an act measured by the reported 400,000 downloads and the over one million forum posts (www.wolfquest.org/ about_overview.php).

\section{ANALYSIS}

The two strands of interactivity briefly described - the result of a series of detours and negotiations made necessary by earlier failures - are teaching/learning environments that work in seemingly very different ways, but the communication is disciplined through the same non-human actant. The simplest form labyrinth interactivity - functions as a visualized presentation of ideas. These ideas are available through a series of choices presented by the interface. The interface - the nonhuman actant - allows the visitor to navigate information made available, but does not afford her any active way of communicating her interpretation of the space back to the museum, since her expressions are limited by the pre-programmed alternatives handed down to the interactive display from the museum. Hence the non-human actant allows the visitor to react to what is presented, but does not allow her to act. Labyrinth interactivity is therefore the freedom of choosing from available versions of stories, consequently navigating conflicting themes, and choosing from a variety of media representing aspects of these stories. As the description implies, these stories can be navigated as a labyrinth where the visitor may choose different paths on the way through the information space controlling order, selection and pace. This interactive setting is a closed space where the visitor is only free to transmit within its borders.

Simulacra interactivity gives you a role to play. By playing this role, you learn about its relations in the surrounding world. The simulacra interactivity functions as a visualized presentation of these relations, setting up rules for how certain reactions foster subsequent reactions. However, these relations are figures based on pre-programmed conclusions that are enforced by the non-human actantt. In your role you try to solve a problem - how to find food - but the tools at hand only let you proceed in ways the non-human actant deems right. By utilizing knowledge gained outside the role, the player evolves the simulacra interactivity, making the experience richer by applying a layer of insights to the motions of the role. This creates what Baudrillard calls the hyperreal; something more than what is imitated, augmented into a perfected reality through the ambition of mimicking reality. This is analogue to the physical interactivity present at natural science museums, where the reality of the effect is the starting point and a state is conjured where the interaction of the user produces that effect through movements that are tropic to the actual relations.

Though both of the described strands of interactivity allow movements, what sets them apart is the way the non-human actant disciplines the movements of the user; the forced movement within the created borders of the labyrinth interactivity or the forced movements within the created digital body of the Simulacra interactivity. The first presents a finite material for the body to arrange in a finite number of possible ways while the second puts you in a digital body that operates in a world 
56 with clear and unbreakable rules. Even though they seem disparate, what unifies these spaces is how they displace action with reaction and thus - through the non-human actant - limits the communication to choices within the established knowledge space. The museum shoulders the role as a guiding subject who, gracefully, reaches out to another subject, the visitor, and asks her to voice her meaning through the interactive space. By putting the answering subject into a milieu built by the enquiring subject, the latter controls the possible expressions of the former. Thus all choice given in the interactive sphere is by consequence a disciplining of the respondent into a knowledge space controlled by the instigator (Westin 2009). However, even Actant $\mathrm{A}$, the instigator, has been disciplined into certain expressions by the non-human actant.

When Actant $A$ wishes to communicate with Actant C, Actant B forces Actant A to express this communication through specific questions and responses. In the interactive visualization of the Sanctuary of Hercules Victor, this is expressed by Actant $\mathrm{A}$ through the indirect question "how do you think it might have looked?", a question that must be answered by Actant $C$ through the series of possible responses presented by Actant $\mathrm{B}$ in the interface. There is no way for the visitor to point out a fourth or fifth option based on her own expertise and truly partake in the dialogue on her own terms. The museum's knowledge space remains intact, and unchallenged, since no other voice can make itself heard.

In WolfQuest, the power relation is established by Actant A through the indirect question "how do you wish to notify your pack?", a question that must be answered by Actant $\mathrm{C}$ through the series of possible

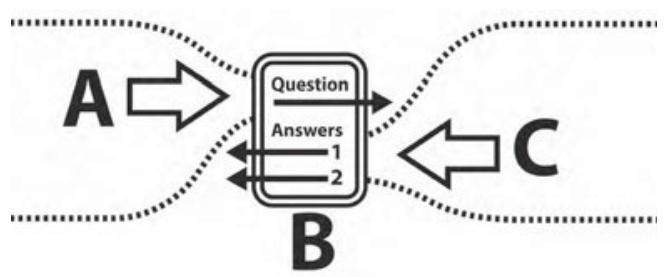

Fig 3: Both the museum's and the visitor's knowledge spaces are mediated, and thus translated, by the narrow interactive space. () 2011 J. Westin.

responses presented by Actant $\mathrm{B}$ in the interface. If Actant $\mathrm{A}$ has decided that a wolf can only contact other wolfs through a certain behaviour, then that behaviour is by code the only one that is accepted by Actant B. The visitor must play along even if she has other additional ideas about how to solve the problem. The question changes from "what can I as a wolf do?" to "what would EduWeb and their enrolled experts think a wolf would do and how have they translated that behaviour to WolfQuest?". Thus, action is in all instances displaced by reaction, confined to a few permitted responses, and a vast knowledge space is narrowed down to fit within the interface of the interactive space (fig. 3).

When designing an interactive interface the museum essentially locks it down; it brings its building blocks to the table, blocks that the visitor could arrange in a number of ways, but the museum will not allow them to be replaced. However, this analogy is intentionally flawed at an actual table the visitor, if unhappy with the present selection of building blocks, could clear some of them away and empty her bag right there, exposing to the museum and other visitors her selection, and build a structure true to her message. It might not look as professional as those built by the museum's 
blocks, but it would be a more honest answer to the museum's wish that the visitor's voice be heard. There is no non-human actant there at the table to discipline her response and stop her from partaking in the dialogue on her own terms, even though, admittedly, all the nonhuman actants that make up a museum environment could have enough of an intimidating effect to make her not to.

Back in the interactive space, all movements are disciplined by the available options in the interface - a digitized selection of the museum's knowledge put there at the birth of the nonhuman actant and since then enforced by the interface - and there is no channel that allows the visitor to express herself outside the building blocks the museum hands her. There is no digital equivalent of clearing the table and emptying your own bag of experiences and ideas. So why do the museums then keep asking the visitor to make her voice heard when all she can do is choose between answers given to her?

\section{CONCLUSION}

The technologies at the heart of the future of museums are all communicative technologies, and in all communication there are at least three actants; two communicating actants and the medium through which they communicate, be it voice, signs or technology. In this study I have described, through a generalized symmetry, a specific technology the interactive display - as an actant exercising the same autonomy as the other actants. This raises the non-human actant to the same level as the human actants and emphasizes how it controls an equal part of the communication in an exhibition. The non-human actant is initially programmed by the instigating actant

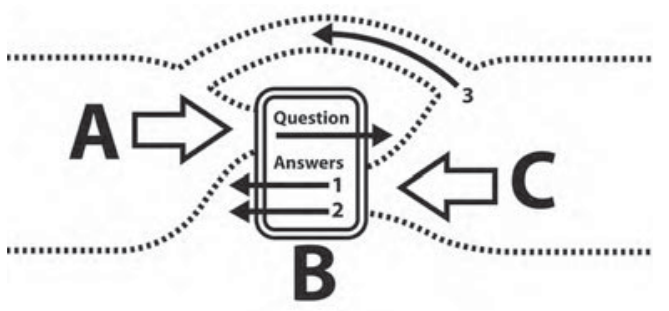

Fig 4: An alternative channel outside the interactive space, which permits a less constrained communication. (C) 2011 J. Westin.

to engage the visitor and make her a part of the exhibition, but, as I have shown, functions as an autonomous actant in the communicative exchange, which limits the dialogue to the museum's knowledge space rather than including the visitor's.

I have described two interactive situations, each representing a typical example from a distinguishable form of interactivity. In both examples there has been a network consisting of three macro-actants; Communicating Actant A, Mediating Actant B and Communicating Actant C. When Actant A and Actant $\mathrm{C}$ wish to communicate they have to go through Actant $\mathrm{B}$, the non-human actant. What lacks in both models is an element of feedback from Actant $\mathrm{C}$ that alters the fundamentals of the interactivity, and transforms it beyond the intentions of the initial action by breaking the fishbowl all interactivity resides in. The simulacra interactivity described, however, had established a communication channel outside the interactive space in the form of the available "wolf biologists" and a dedicated forum. The user, if enterprising, could turn to these channels and establish a dialogue about the subject where she can express herself in a way not permitted within the interactive space.

This holds true in a museum context; when 
58 employing interactive displays aimed at creating a communication with the visitor $-\mathrm{a}$ communication where the visitor's input is taken seriously - you also have to provide a channel outside the interactive space where the visitor can express her thoughts about the experience (fig. 4). As stated in the introduction; interactivity is a great pedagogic tool since the visitor is free to navigate a large amount of information at her own pace. However, most interactive models can never be a source of information beyond the scoop of their creator - they can never in themselves be a dialogue between museum and visitor. By itself, an interactive display does not challenge authority but instead reinforces it through discipline.

It is a challenge to find a pedagogic approach that opens up a technology to action instead of reaction, by-passing the inherent subjectobject relation of the museum. A visitor could very well be better informed about a certain subject than the museum, but interactive displays in their current form, I argue, do not offer an opportunity for these visitors to express themselves and share their knowledge, as a consequence of the non-human actants. By acknowledging the non-human actant's role in disciplining any communicative exchange, museums and developers can take steps to minimize its effect and deploy several layers of interaction to allow both the museum and the visitor as much freedom in their expressions as possible.

\section{References}

Anzai, Yayoi: "Play and learn with mobile technology". ED-MEDIA 2009 Proceedings. AACE: Chesapeake 2009: 3520-3526.

Arnold, David: "Digital artefacts: possibilities and purpose". Greengrass, M. and Hughes, L. (eds.)
The virtual representation of the past. Ashgate: London 2008: 159-170.

Awouters, Valère et al: Awouters, V., Jans, R., Jans, S., Veltjen, A. "How can teachers integrate games in their education". ED-MEDIA 2009 Proceedings. AACE: Chesapeake 2009: 2720-2724.

Barry, Andrew: Political machines - governing a technological society. Athlone: London 2001.

Baudrillard, Jean: "Simulacra and simulations". Poster, M. (ed.) Selected writings. Stanford University Press: Stanford 1988: 166-184.

BBC 18.01.08: http://news.bbc.co.uk/2/hi/technology/7195718.stm. Accessed on 21 January 2011.

Callon, Michel: "Some elements of a sociology of translation: domestication of the scallops and the fishermen of St. Brieuc Bay". Law, J. (ed.) Power, action and belief: a new sociology of knowledge? Routledge: London 1986: 196-223.

Cooper, Tessa et al: Cooper, T., Carroll, S.P., Liu, C., Franklin, T., Chelberg, D. "Using the virtual world of second life to create educational games for real world middle school science classrooms". ED-MEDIA 2009 Proceedings. AACE: Chesapeake 2009: 2124-2134.

Doel, Marcus A. and Clarke, David B.: "Virtual worlds - simulation, suppletion, s(ed)ucrion and simulacra”. Crang, M., Crang, P. and May, J. (eds.) Virtual Geographies - bodies, space and relations. Routledge: London 1999: 261-283.

Foucault, Michel: The history of sexuality, 1: an introduction. Pantheon Books: New York 1978.

Goodwin, Charles: "Professional vision". American Anthropologist. No 3, 1996: 606-633.

Grahn, Wera: "Från vardagsföremål till museala fakta”. Aronsson, I. and Meurling, B. (eds.) Det bekönade museet. Uppsala universitet: Uppsala 2005: 95-122.

Greenfield, Patricia M.: "Technology and informal education: what is taught, what is learned". Science. No 323, 2009: 71-69.

Hazan, Susan: "A crisis of authority: New lamps for 
old". Cameron, F. and Kenderdine, S. (eds.) Theorizing digital cultural heritage - a critical discourse. The MIT Press: London 2007: 133-148.

Hermon, Sorin: "Reasoning in 3D: a critical appraisal of the role of $3 \mathrm{~d}$ modelling and virtual reconstructions in archaeology". Frischer, B. and Dakouri-Hild, A. (eds.) Beyond illustration: 2D and $3 D$ digital technologies as tools for discovery in archaeology. Archeopress: Oxford 2008: 36-45.

Ivarsson, Jonas: "Developing the construction sight: architectural education and technological change". Visual Communication. No 9, 2010: 171-191.

Kahr-Højland, Anne: "Brave new world: mobile phones, museums and learning". Nordisk Museologi. No 1, 2007: 3-19.

Kenderdine, Sarah: "Speaking in rama”. Cameron, F. and Kenderdine, S. (eds.) Theorizing digital cultural heritage - a critical discourse, 2007: 301-332. UTG, ORT

Latour, Bruno and Callon, Michel: "Uscrewing the big Leviathan: how macro-structure reality and how sociologists help them to do so". KnorrCetina, K and Cicourel, A. V. (eds.) Advances in social theory and methodology: toward an integration of micro- and macro-sociologies. Routledge: London 1986: 277-303.

Latour, Bruno: "Visualisation and cognition". Hess, D., Layne, L. and Rip, A. (eds.) Knowledge and society: studies in the sociology of culture past and present. No 6, 1986: 1-40.

Latour, Bruno: "Where are the missing masses?: the sociology of a few mundane artifacts". Bijker, W. E. and Law, J. (eds.) Shaping technology/building society. The MIT Press: London 1992: 225-258.

Latour, Bruno: "Ethnography of a 'high-tech' case". Lemmonier, P. (ed.) Technological choices. Routledge: London 1993: 372-398.

Latour, Bruno: Reassembling the social. Oxford University Press: Oxford 2005.

Laughlin, Daniel: www.fas.org/programs/ltp/publications/NASA\%20eEducation\%20Roadmap.pdf,
2007. Accessed on 21 January 2011.

Lee, Chien-Sing: "Scaffolding everyday creativity: a spiral cascaded curriculum development approach". ED-MEDIA 2009 Proceedings. AACE: Chesapeake 2009: 770-775.

Santillo Frizell, Barbro and Westin, Jonathan: "Displaying Via Tecta”. Bjur, H. and Santillo Frizell, B. (eds.) Via Tiburtina: space, movement and artefacts in the urban landscape. Acta Instituti Romani Regni Sueciae: Motala 2009: 219-230.

Stead, Naomi: "The semblance of populism: National Museum of Australia". The Journal of Architecture. No 9, 2004: 386-397.

Westin, Jonathan: "Interactivity, reactivity and activity: thoughts on creating a digital sphere for an analogue body". ED-MEDIA 2009 Proceedings. AACE: Chesapeake 2009: 814-819.

Westin, Jonathan and Eriksson, Thommy: "Imaging the Sanctuary of Hercules Victor". Bernardini, F. and Santarsiero, D. (eds.) Archeomatica. No 2, 2010: 58-62.

Wired 21.01.2008: www.wired.com/wiredscience/2008/01/would-you-play. Accessed on $21 \mathrm{Ja}-$ nuary 2011.

Wired 22.01.2008: http://blog.wired.com/wiredscience/2008/01/nasa-seeks-inpu.html. Accessed on 21 January 2011.

Witcomb, Andrea: "The materiality of virtual technologies”. Cameron, F. and Kenderdine, S. (eds.) Theorizing digital cultural heritage - a critical discourse. The MIT Press: London 2007: 35-48.

\section{*onathan Westin, M.A, PhD-student}

Address: Department of Conservation, University of Gothenburg, Box 130,

SE-405 30 Göteborg,

Sweden

E-mail: jonathan.westin@gu.se 